\title{
Cytogenetic and Molecular Study of an Adult Sclerosing Rhabdomyosarcoma of the Extremity: MYOD1-mutation and Clonal Evolution
}

\author{
LUDMILA GORUNOVA ${ }^{1}$, BODIL BJERKEHAGEN ${ }^{2,3,4}$, FRANCESCA MICCI $^{1}$, \\ SVERRE HEIM ${ }^{1,3}$ and IOANNIS PANAGOPOULOS ${ }^{1}$ \\ ${ }^{1}$ Section for Cancer Cytogenetics, Institute for Cancer Genetics and Informatics, \\ The Norwegian Radium Hospital, Oslo University Hospital, Oslo, Norway; \\ ${ }^{2}$ Department of Pathology, The Norwegian Radium Hospital, Oslo University Hospital, Oslo, Norway; \\ ${ }^{3}$ Institute of Clinical Medicine, Faculty of Medicine, University of Oslo, Oslo, Norway; \\ ${ }^{4}$ Institute of Oral Biology, University of Oslo, Oslo, Norway
}

\begin{abstract}
Background: Spindle cell/sclerosing rhabdomyosarcoma is a genomically heterogeneous, uncommon subtype of rhabdomyosarcoma, particularly rare in adults. Its MYOD1-mutant variant is aggressive irrespective of age. Cytogenetic data on spindle cell/sclerosing rhabdomyosarcoma are sparse and disparate. Materials and Methods: Cytogenetic and molecular analyses were performed on an adult sclerosing rhabdomyosarcoma. Results: The karyotype of the sclerosing rhabdomyosarcoma displayed clonal evolution corresponding to two hyperdiploid clones: $48, X Y,+i(19)(p 10),+22 /$ 48 ,idem,der(9)t(2;9)(q21 22;p21). The changes were gain of chromosome 19 with the overrepresentation of $19 p \mathrm{arm}$, gain of chromosome 22, gain of the $2 q$ arm, and loss of $9 p 21$. Mutation analysis revealed a homozygous c.T365G (p.L122R) mutation of the MYODI gene, but none of PIK3CA. Conclusion: To our knowledge, this is the first adult MYOD1mutant sclerosing rhabdomyosarcoma studied cytogenetically. The only other reported sclerosing rhabdomyosarcoma with MYOD1 mutation and abnormal karyotype was pediatric. Since these tumors are highly aggressive, further studies unravelling their cytogenetic and molecular characteristics are warranted.
\end{abstract}

This article is freely accessible online.

Correspondence to: Ludmila Gorunova, Section for Cancer Cytogenetics, Institute for Cancer Genetics and Informatics, The Norwegian Radium Hospital, Oslo University Hospital, Montebello, PO Box 4954 Nydalen, NO-0424 Oslo, Norway. Tel: +47 22782362, e-mail: ludmila.gorunova@rr-research.no

Key Words: Adult sclerosing rhabdomyosarcoma, MYOD1-mutation, chromosome aberrations, clonal evolution. This article is freely accessible online.
Rhabdomyosarcoma (RMS) is a malignant soft tissue tumor with skeletal muscle differentiation. It is the most common soft tissue sarcoma in children, accounting for 5-8\% of all pediatric malignancies, but rare in adults where it makes up less than $5 \%$ of all sarcomas $(1,2)$. The current 2013 WHO classification of tumors of soft tissue and bone recognizes four histological RMS subtypes: embryonal (ERMS), alveolar (ARMS), pleomorphic (PRMS), and the recently added spindle cell/sclerosing RMS.

Spindle cell/sclerosing RMS is an uncommon variant of RMS with spindle cell morphology. It accounts for 5-10\% of all RMS cases and affects both children and adults (3). In the pediatric population, tumors with spindle cell morphology arise predominantly in the paratesticular region, whereas more than half of the adult cases occur in the head and neck (3). Lesions with sclerosing morphology in both age groups are most common in the head and neck and the limbs $(3,4)$. Microscopically, spindle cell RMS is composed of a predominant population of spindled neoplastic cells with ovoid or elongated nuclei and eosinophilic cytoplasm. Occasionally, RMS with spindle cell morphology may show focal, subtotal or total stromal hyalinization with cells arranged in nests, microalveoli, or trabeculae, imparting a pseudovascular appearance, and characterizing the more rare sclerosing variant (3).

The subclassification of RMS, mainly based on histological criteria, collates with molecular genetic and cytogenetic differences among the subtypes, reflecting their diverse pathogenetic pathways. The cytogenetic hallmarks of ARMS are the specific chromosome translocations $t(2 ; 13)(q 36 ; q 14)$ and, more rarely, $\mathrm{t}(1 ; 13)(\mathrm{p} 36 ; \mathrm{q} 14)$ leading to formation of the fusion genes $P A X 3-F O X O 1$ and $P A X 7-F O X O 1$, respectively (PAX3 in 2q36, FOXO1 in 13q14, PAX7 in 1p36) (5-7). About $20 \%$ of ARMSs are negative for these fusions, but then variant 
gene fusions are sometimes found, such as $P A X 3$ fused to FOXO4 (in Xq13), to NCOAI (in 2p23), to INO8OD (in $2 \mathrm{q} 33$ ), or to NCOA2 (in 8q13) $(6,7)$. Whereas fusion-positive ARMS is a highly aggressive neoplasm, the prognosis of fusion-negative ARMS is more favorable and similar to that of ERMS (5). The majority of ERMSs are hypo- or hyperdiploid and carry multiple numerical changes, the most common of which are gains of chromosomes 2, 7, 8, 11, 12, and 13 and losses in $1 \mathrm{p}$ and 14q; no specific or recurrent structural aberrations have been reported (6). PRMS, an uncommon high-grade sarcoma, occurs generally in older adults and displays highly complex karyotypes (6).

Although spindle cell/sclerosing RMS is a relatively new and uncommon entity, much progress was made in unravelling its molecular genetic characteristics. It has become clear that, in spite of the unifying terminology, this subtype of RMS is genomically heterogeneous $(1,4)$. At present, three groups have emerged according to molecular data: 1) spindle cell and sclerosing RMSs, both pediatric and adult, with MYODI mutations; 2) congenital and infantile spindle cell RMSs with VGLL2 and NCOA2 associated gene fusions; and 3) spindle cell RMSs with no known recurrent alterations (4). The prognosis of RMS patients differs significantly among the groups: whereas infantile tumors mostly allow for a favorable clinical course, the MYOD1mutated sarcomas have, irrespective of age, a significantly worse prognosis, even when therapy is aggressive (4).

An understanding of the pathogenetic mechanisms behind spindle cell/sclerosing RMS is of vital importance for the refinement of their diagnosis, prognosis, and treatment. In this regard the cytogenetic approach, which provides a genomewide overview of chromosome alterations, could be instrumental, as it is known to be for many neoplastic disorders, including sarcomas. However, due to the rarity of spindle cell/sclerosing RMS, the current cytogenetic literature is sparse and to some extent disparate in this regard.

As part of our diagnostic practice we recently analyzed cytogenetically as well as molecularly an adult sclerosing RMS. Here we report the chromosome abnormalities and mutation data characterizing that tumor and discuss the relevant literature.

\section{Materials and methods}

Ethics statement. The study was approved by the regional ethics committee (Regional komité for medisinsk forskningsetikk Sør-Øst, Norge, http://helseforskning.etikkom.no; 2010/1389/REK sør- øst A). Written informed consent was obtained. The Ethics Committee's approval included a review of the consent procedure. All patient information has been de-identified.

Case description. A 30-year-old male presented with a fast-growing soft tissue tumor sized $11 \mathrm{~cm}$ in the left foot (Figure 1A). After a biopsy, amputation was performed. Histological examination showed a cellular spindle cell tumor with elongated nuclei (Figure 1B) and areas of sclerotic tissue with cells surrounded by hyalinized collagen fibers with some necrotic parts (Figure 1C). Small areas displayed a pseudoangiomatoid growth pattern (Figure 1D). Mitotic figures were $18 / 10$ high power field $\left(1,734 \mathrm{~mm}^{2}\right)$. The tumor was classified as high grade malignant, grade 3 according to the French grading system of soft tissue tumors (8). Immunohistochemistry showed strong positive nucleic staining for MYOD1 (Figure 1E) as well as positive findings for smooth muscle actin, CD99, and CD56 but only focal staining for desmin, Myf-4, and myogenin. There was negative staining for caldesmon, actin, CD31, ERG, CD34, TLE1, TFE3, SOX-10, and MUC4. The patient is alive after a follow-up time of 28 months.

Chromosome banding. Fresh tissue from the specimen was disaggregated mechanically and enzymatically with collagenase II (Worthington, Freehold, NJ, USA). The cells were cultured and harvested using standard techniques (9). Chromosome preparations were G-banded with Wright's stain (Sigma-Aldrich; St Louis, MO, USA). Metaphases were analyzed and karyograms prepared using the CytoVision computer assisted karyotyping system (Leica Biosystems, Newcastle, UK). The karyotypes were written according to the International System for Human Cytogenomic Nomenclature (10).

Mutation analysis of MYOD1 and PIK3CA genes. Genomic DNA was extracted from tumor sample using the Maxwell 16 Instrument System and the Maxwell 16 Tissue DNA Purification Kit (Promega, Madison, WI, USA). The concentration and purity of DNA were measured using a QIAxpert microfluidic UV/VIS spectrophotometer (Qiagen, Hilden, Germany). The methodology for the mutation analysis of the MYOD1 and PIK3CA genes was as described by Agaram and coworkers (11). The PCR products were purified using the MinElute PCR Purification Kit (Qiagen) and analyzed by direct sequencing using the dideoxy procedure with the BigDye terminator v1.1 cycle sequencing kit (ThermoFisher Scientific, Waltman, MA, USA) on the Applied Biosystems Model 3500 Genetic Analyzer sequencing system. BLAST (http://blast.ncbi.nlm.nih.gov/Blast.cgi) was used for computer analysis of sequence data.

\section{Results}

G-banding analysis of metaphase plates from 35 short-term cultured tumor cells showed chromosome abnormalities corresponding to two related hyperdiploid clones:

48,XY,+i(19)(p10),+22[10]/48,idem,der(9)t(2;9)(q21 22;p21

) [25] (Figure 2A). The clones were stable, demonstrated clonal evolution, and exhibited in total two numerical and two structural changes. In the first clone, two extra copies of the short arm of chromosome 19 were found in the form of an isochromosome, together with trisomy 22 . The second clone showed an additional unbalanced translocation leading to partial gain of the long arm of chromosome 2 (q21 22qter) as well as partial loss of the short arm of chromosome 9 (p21-pter).

Mutation analysis of the MYOD1 gene revealed that the tumor harbored a homozygous c.T365G (p.L122R) mutation (Figure 2B). No mutations in the helical domain (E542K and E545K) or kinase domain (H1047) of PIK3CA were found (data not shown). 

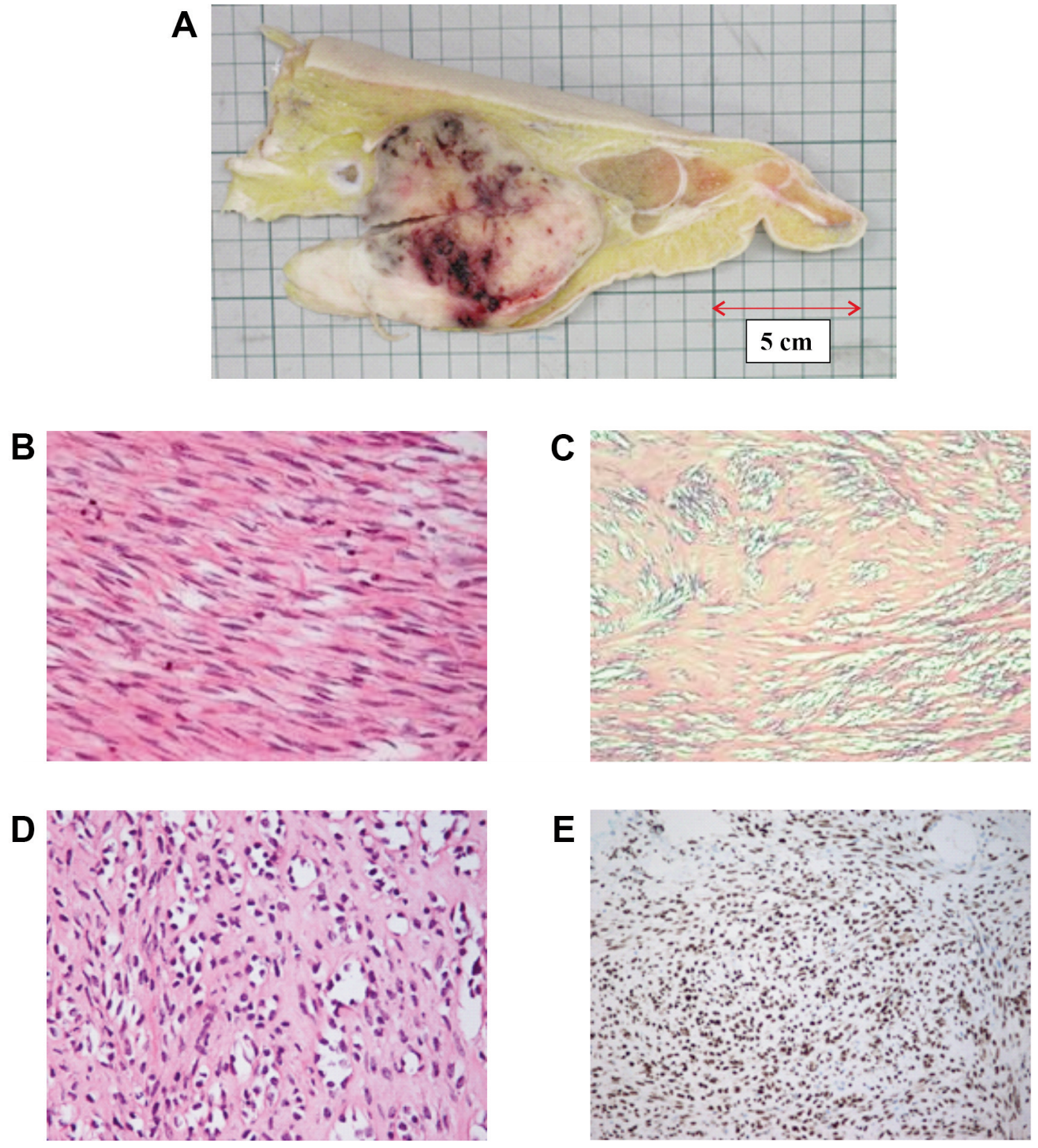

Figure 1. Pathologic examination of the adult sclerosing rhabdomyosarcoma. A) Sagittal photo of the $11 \mathrm{~cm}$ large soft tissue tumor in the foot. B) Hematoxylin and eosin $(H \& E)$-stained section showing the spindle cell morphology. $C) H \& E$-stained section displaying the sclerotic areas. D) $H \& E$ stained section showing the pseudoangiomatoid growth pattern. E) Immunohistochemical examination demonstrating strong nuclear staining for MYOD1.

\section{Discussion}

Spindle cell/sclerosing RMS was recently separated from ERMS as a stand-alone entity based on its distinctive morphologic features but was later subdivided into three groups according to molecular data: 1) spindle cell and sclerosing RMSs, both pediatric and adult, with MYODI mutations; 2) congenital/infantile spindle cell RMSs with VGLL2 and NCOA2 associated gene fusions; 3) spindle cell RMSs with no known recurrent alterations $(1,4)$.
The MYOD1 mutations in RMS were first found in 2014 by two independent groups $(12,13)$. In a very recent and large study, MYOD1-mutations were described in 30 spindle cell/sclerosing RMSs from patients of all ages (4). Eight tumors showed pure spindle cell morphology, eight had pure sclerosing morphology, while the rest showed mixed features. In children, there was a female predilection, whereas gender distribution was equal in adults.

The MYODl gene encodes a nuclear protein that belongs to the basic helix-loop-helix (bHLH) family of transcription 
A

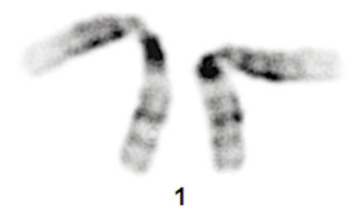

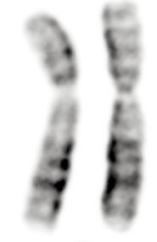

2

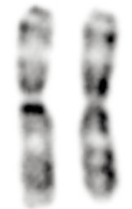

3

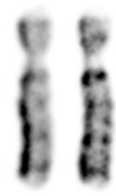

4

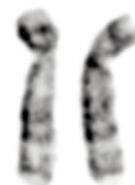

5

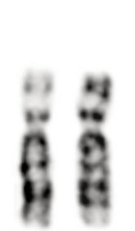

6

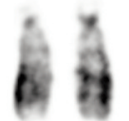

13

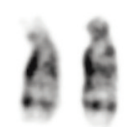

14

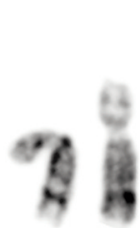

8

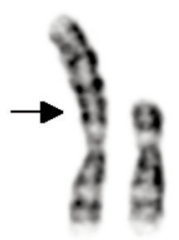

9

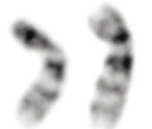

10

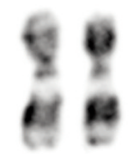

11

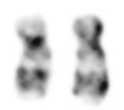

17

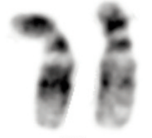

12

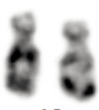

18
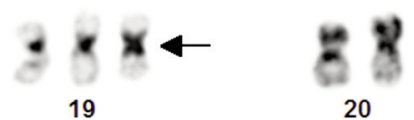

20
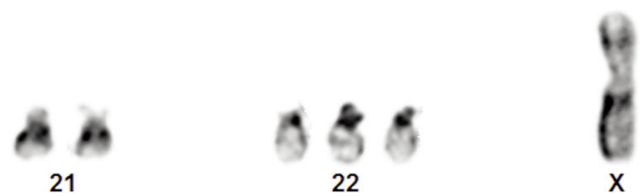

B

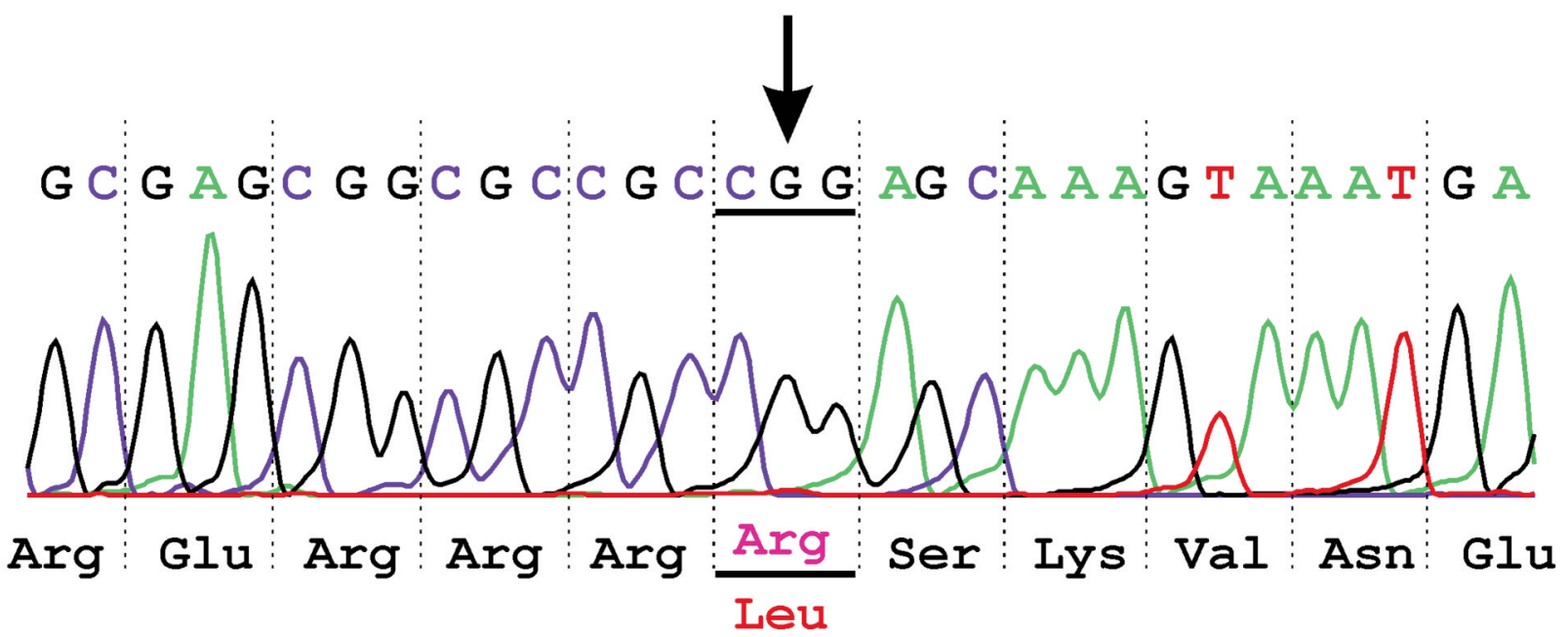

Figure 2. Cytogenetic and molecular analyses of the adult sclerosing rhabdomyosarcoma. A) Representative karyogram of the tumor cells demonstrating clonal chromosome aberrations; breakpoints are shown by arrows. B) Partial sequence chromatogram showing the substitution T$>G$ at the position 365 of the coding sequence of the MYOD1 gene (c.365T>G). The mutation resulted in the amino acid mutation p.L122R (substitution-missense position 122 Leucine ->Arginine). The detected mutation is homozygous. The wild-type T-peak is barely discernable.

factors and the subfamily of myogenic factors. MYOD1 regulates muscle cell differentiation by inducing cell cycle arrest, a prerequisite for myogenic differentiation (4). Mutation of Leu 122 to Arg in MYOD1 confers reduced transcriptional activation at MYOD1 target genes, together with enhanced binding to MYC target sites (11-14). The mutated gene has a dominant negative function; mutations may be homo- or heterozygous $(1,4)$. In the aforementioned 
Gorunova et al: MYOD1-mutant Adult Sclerosing Rhabdomyosarcoma

Table I. Cytogenetic and molecular genetic alterations in the spindle cell/sclerosing rhabdomyosarcomas.

\begin{tabular}{|c|c|c|c|c|c|c|}
\hline Case & Age/Gender & Location & Karyotype & MYOD1 status & Diagnosis & Reference \\
\hline 1 & $11 / \mathrm{M}$ & Elbow & 48,XY,add(6)(q15),+11,+19 & nd & Sclerosing RMS & (16) \\
\hline 2 & $12 / \mathrm{M}$ & Masseter & $47, \mathrm{XY},-3$, ?add(12)(p12),+2mar,inc/94,idemx2,+2mar & nd & Sclerosing RMS & \\
\hline 3 & $79 / \mathrm{F}$ & Lower leg & $44 \sim 49, \mathrm{XX},+\operatorname{del}(1)(\mathrm{p} 22),+\mathbf{1 1},+16,+18,+21,-22$ & nd & Sclerosing RMS & (17) \\
\hline 4 & 18/M & Thigh & $\begin{array}{c}55 \sim 60, X Y,+X,+Y,+\operatorname{add}(1)(q 42),+2,+7,+8,+9,+12, \text { add }(12) \\
(q 13),+14,+19,+20\end{array}$ & nd & Sclerosing RMS & (18) \\
\hline 5 & $17 / \mathrm{F}$ & Lower leg & $46, \mathrm{XX}, \mathrm{t}(5 ; 20)(\mathrm{q} 31 ; \mathrm{p} 13)$ & nd & Sclerosing RMS & \\
\hline 6 & $3.5 / \mathrm{F}$ & Thigh & 46,XX,del(6)(q15q23),der(13)t(1;13)(q12;q21) & p.L122R mutation & Sclerosing RMS & (15) \\
\hline 7 & $30 / \mathrm{M}$ & Foot & $48, \mathrm{XY},+\mathrm{i}(19)(\mathrm{p} 10),+22 / 48, \operatorname{idem}, \operatorname{der}(9) \mathrm{t}(2 ; 9)(\mathrm{q} 21 \sim 22 ; \mathrm{p} 21)$ & $\begin{array}{l}\text { p.L122R mutation } \\
\text { (homozygous) }\end{array}$ & Sclerosing RMS & $\begin{array}{l}\text { Present } \\
\text { study }\end{array}$ \\
\hline 8 & $7 \mathrm{mo} / \mathrm{M}$ & $\begin{array}{c}\text { Posterior } \\
\text { neck }\end{array}$ & $\begin{array}{c}46, \mathrm{XY}, \mathrm{t}(6 ; 8)(\mathrm{p} 12 ; \mathrm{q} 11) \\
S R F-N C O A 2 \text { fusion gene } \\
(S R F \text { in } 6 \mathrm{p} 21 ; \text { NCOA2 in } 8 \mathrm{q} 13)\end{array}$ & nd & $\begin{array}{l}\text { Congenital/ } \\
\text { infantile spindle } \\
\text { cell RMS }\end{array}$ & $(19,20)$ \\
\hline 9 & $4 \mathrm{wk} / \mathrm{M}$ & Chest wall & $\begin{array}{c}58, \mathrm{XY},-\mathrm{X},-1,-3,-6,-8,-9,-10, \operatorname{der}(11) \mathrm{t}(8 ; 11)(\mathrm{q} 13 ; \mathrm{p} 13),-16 \\
-17,-18,-19,-21,-22,+2 \mathrm{r} \\
\text { TEAD } 1-N C O A 2 \text { fusion gene } \\
(T E A D 1 \text { in } 11 \mathrm{p} 15 ; N C O A 2 \text { in } 8 \mathrm{q} 13)\end{array}$ & nd & $\begin{array}{l}\text { Congenital/ } \\
\text { infantile spindle } \\
\text { cell RMS }\end{array}$ & (20) \\
\hline 10 & $38 / \mathrm{F}$ & Cheek & $\begin{array}{c}45, \mathrm{X}, \mathrm{X},-2, \operatorname{add}(3)(\mathrm{p} 24), \operatorname{add}(6)(\mathrm{p} 21), \operatorname{add}(11)(\mathrm{q} 23) \\
-12,+2 \mathrm{mar}\end{array}$ & nd & Spindle cell RMS & (21) \\
\hline 11 & $56 / \mathrm{M}$ & $\begin{array}{l}\text { Hemidia- } \\
\text { phragm }\end{array}$ & $\begin{array}{c}89,-X,-X,-Y,-Y,-4,-4,-7,-7,-8,-8,-9,-9,-11,-11,-14,-14,-20 \\
-20,-21,-21,+17 \mathrm{mar}\end{array}$ & nd & Spindle cell RMS & \\
\hline 12 & $6 / \mathrm{M}$ & $\begin{array}{c}\text { Parotid } \\
\text { gland }\end{array}$ & $\begin{array}{c}59, \mathrm{XY},-1,-3,-4,-5,-6,+8,+8,+\operatorname{del}(8)(\mathrm{q} 22 \mathrm{q} 24),-9,-10, \operatorname{del}(12) \\
(\mathrm{q} 13),-15,-16,-17,-18, \operatorname{der}(21) \mathrm{t}(12 ; 21)(\mathrm{p} 11 ; \mathrm{p} 11),-22, \operatorname{der}(22) \\
\mathrm{t}(1 ; 22)(\mathrm{q} 12 ; \mathrm{p} 11)\end{array}$ & nd & Spindle cell RMS & (22) \\
\hline 13 & $18 / \mathrm{F}$ & Cheek & $\begin{array}{c}46, \mathrm{XX}, \operatorname{der}(2) \mathrm{t}(2 ; 7)(\mathrm{q} 36 \sim 37 ; \mathrm{q} ? 3), \operatorname{del}(14)(\mathrm{q} 24), \operatorname{der}(16) \\
\mathrm{t}(1 ; 16)(\mathrm{q} 21 ; \mathrm{q} 13)\end{array}$ & nd & Spindle cell RMS & (23) \\
\hline
\end{tabular}

Age: In years, if not otherwise specified; mo, month; wk, week. nd, not determined. In bold - recurrent chromosome changes in sclerosing RMS.

study (4), $73 \%$ of the tumors showed homozygosity for MYOD1 mutations.

In line with this data, we also found a homozygous MYODI c.T365G (p.L122R) mutation in the sample of sclerosing RMS we examined. Since about one third of MYOD1-mutant RMSs harbor co-existing PIK3CA mutations either in the helical domain (E542K, E545K) or kinase domain (H1047R) $(4,12)$, we searched for mutations at these hotspots but found none.

To our knowledge, the present sarcoma is the first adult sclerosing RMS for which both cytogenetic data and MYODI mutation status are described. The only other reported karyotypically abnormal MYODI-mutant sclerosing RMS was pediatric (15).

To clarify the cytogenetic characteristics of spindle cell/sclerosing RMSs, we summarized the reported chromosome data, including the present case, in Table I. The relevant literature is not fully consistent, probably for the following reasons. First, the histologic classification of RMS underwent revisions over the time during which the karyotypic descriptions were reported. Second, the earlier cytogenetic studies lack critical molecular information, not least about MYOD1 gene status. In view of recent refinements in RMS sub-grouping, this detracts a lot from the value of comparisons.
We arranged cases according to the morphology reported in the original articles and the molecular features described (15-23). As it follows from several publications $(11,13,14)$, RMSs with sclerosing morphology consistently harbor MYOD 1 mutations whereas only up to $40 \%$ of spindle cell tumors are $M Y O D 1$-positive. We therefore choose to place all reported sclerosing RMSs (15-18), including the present case, in a separate group, irrespective of their MYOD1 status (Table I, cases 1-7).

To date, seven karyotypes of sclerosing RMSs have been reported; five tumors were pediatric and two adult ( $>18$ years old). All but two tumors (cases 1-4 and 7) were hyperdiploid and displayed mostly numerical changes, accompanied by 13 structural abnormalities, whereas the remaining two tumors (cases 5 and 6) were pseudodiploid and exhibited only 1-2 structural changes. Though none of the structural changes in this group was recurrent, chromosome 1 (specifically gain of 1q), chromosome 6 (loss in 6q), and chromosome 12 were involved more than once. Numerical changes were almost exclusively chromosomal gains, two of which were recurrent: the most common was $+19 / 1$ (19), found in three tumors (cases 1, 4, and 7), whereas +11 was seen twice (cases 1 and 3 ).

The karyotypic features of this group of sclerosing RMSs, such as near- or hyperdiploid range, the overrepresentation of 
gains among numerical changes, the recurrent trisomies of particular chromosomes, such as 11 and 19, is reminiscent of the chromosome aberration pattern seen in ERMS. In that tumor type, gains of chromosomes 11/der(11) and 19/der(19) have been reported in $20-25 \%$ of cases (24). Chiles and coworkers (16) reported the first karyotypes of pediatric sclerosing RMSs whereas Croes and coworkers (17) provided the first karyotypic description of adult sclerosing RMS. Commenting on the karyotypic features of RMS with sclerosing morphology known at that time, the authors emphasized their similarity to the cytogenetic profile of ERMS, in particular the frequent gains of chromosomes 11 and 19. The present study supports the suggestion that nonrandom involvement of chromosome 19 is a feature of sclerosing RMS. Furthermore, the overrepresentation of the 19p (4 copies) compared with the $\mathrm{q}$ arm ( 2 copies) may indicate that this imbalance is important in tumorigenesis. It may in this context be of interest that the deletions in the derivative chromosomes 19 reported in ERMS, occurred almost exclusively in the q arm (24). Yet, the significance of these changes, as well as the degree of involvement of chromosome 19 in sclerosing RMS in general, remains unclear.

The present sclerosing RMS displayed clonal - and hence tumor - evolution leading to overrepresentation of the $2 \mathrm{q}$ arm and deletion of $9 \mathrm{p}$. As far as the former is concerned, extra copies of $2 / 2 q$ is one of the most frequent abnormalities recorded in ERMS, signifying again the closeness between the two subgroups.

Previously, Walther and coworkers (15) used SNP array analysis to find a homozygous deletion in 9p21 affecting genes $C D K N 2 A / B$ in the pediatric $M Y O D 1$-mutant sclerosing RMS they examined (Table I, case 6). Later, Agaram and coworkers (4) applied targeted exome sequencing to detect loss of $C D K N 2 A / B$ in an adult $M Y O D 1$-mutant sclerosing RMS. In the present adult $M Y O D 1$-mutant RMS, the loss of 9 p21 was identified cytogenetically, supporting the molecular data about possible involvement of the tumor suppressor genes $C D K N 2 A / B$ in sclerosing RMS.

Importantly, MYOD1-mutant RMS often is a lethal cancer, irrespective of age and the treatment given, comparable to ARMS, in contrast to the significantly higher survival rate of patients with ERMS (4). Given the small number of sclerosing RMSs analyzed, it is not possible at present to say which - if any - karyotypic features may help differentiate between these two subtypes.

Two RMSs with spindle cell morphology from children younger than one year of age were studied both cytogenetically and molecularly (Table 1, cases 8 and 9) (19, 20). In each case, fusion of the NCOA2 gene (in 8q13) was found, either with $S R F$ (in 6p21) or TEAD1 (in 11p15), thereby corroborating the identified karyotypic abnormalities $(19,20)$. Other recurrent fusions discovered in the subgroup of congenital/infantile spindle cell RMSs with the help of molecular techniques include VGLL2-NCOA2 and VGLL2CITED2 (VGLL2 in 6q22 and CITED2 in 6q24) $(1,4,25)$. The patients in this subgroup followed a favorable clinical course as their tumors seemed to lack metastatic potential.

For the four remaining pediatric and adult spindle cell RMSs, which were investigated cytogenetically much earlier (Table I, cases 10-13), relevant molecular data are missing (2123). Their karyotypes demonstrate numerical and structural changes without apparent similarity among them. They may well belong to the group of spindle cell RMSs without MYOD1 mutations or other defining genetic alterations or might represent ERMSs with spindle cell areas $(1,4)$.

In conclusion, spindle cell/sclerosing RMS is a molecularly and pathogenetically heterogeneous RMS subtype comprising tumors differing in prognosis and clinical outcome. To date, the cytogenetic database on this subtype of RMS is only rudimentary. Further studies are warranted for the identification of recurrent chromosome aberrations in different tumor subsets in order to better understand their underlying pathogenetic mechanisms and clinical behavior.

\section{Conflicts of Interest}

The Authors declare that they have no potential conflicts of interest.

\section{Authors' Contributions}

LG performed cytogenetic analysis, designed the research, and wrote the article. BB performed pathological examination and evaluated clinical data. FM evaluated cytogenetic and molecular results. SH interpreted experimental and clinical data and assisted with writing of the article. IP performed molecular genetic analyses, assisted with experimental design, and supervised the research.

\section{Acknowledgements}

This work was supported by grants from Radiumhospitalets Legater.

\section{References}

1 Leiner $\mathrm{J}$ and Le Loarer $\mathrm{F}$ : The current landscape of rhabdomyosarcomas: an update. Virchows Archiv 476(1): 97-108, 2020. PMID: 31696361. DOI: 10.1007/s00428-019-02676-9

2 Parham DM and Barr FG: Embryonal rhabdomyosarcoma. In: WHO Classification of Tumours of Soft Tissue and Bone. Fletcher CDM, Bridge JA, Hogendoorn PCW and Mertens F (eds.). IARC Press: Lyon, pp. 127-129, 2013.

3 Nascimento AF and Barr FG: Spindle cell/sclerosing rhabdomyosarcoma. In: WHO Classification of Tumours of Soft Tissue and Bone. Fletcher CDM, Bridge JA, Hogendoorn PCW and Mertens F (eds.). IARC Press: Lyon, pp. 134-135, 2013.

4 Agaram NP, LaQuaglia MP, Alaggio R, Zhang L, Fujisawa Y, Ladanyi M, Wexler LH and Antonescu CR: MYOD1-mutant spindle cell and sclerosing rhabdomyosarcoma: an aggressive subtype irrespective of age. A reappraisal for molecular 
classification and risk stratification. Mod Pathol 32(1): 27-36, 2019. PMID: 30181563. DOI: 10.1038/s41379-018-0120-9

5 Parham DM and Barr FG: Alveolar rhabdomyosarcoma. In: WHO Classification of Tumours of Soft Tissue and Bone. Fletcher CDM, Bridge JA, Hogendoorn PCW and Mertens F (eds.). IARC Press: Lyon, pp. 130-132, 2013.

6 Mandahl N and Mertens F: Soft tissue tumors. In: Cancer Cytogenetics: Chromosomal and Molecular Genetic Abberations of Tumor Cells. Fourth Edition ed. Heim S and Mitelman F (eds.). Wiley-Blackwell, pp. 583-614, 2015.

7 Shern JF, Chen L, Chmielecki J, Wei JS, Patidar R, Rosenberg M, Ambrogio L, Auclair D, Wang J, Song YK, Tolman C, Hurd L, Liao H, Zhang S, Bogen D, Brohl AS, Sindiri S, Catchpoole D, Badgett T, Getz G, Mora J, Anderson JR, Skapek SX, Barr FG, Meyerson M, Hawkins DS and Khan J: Comprehensive genomic analysis of rhabdomyosarcoma reveals a landscape of alterations affecting a common genetic axis in fusion-positive and fusion-negative tumors. Cancer Discov 4(2): 216-231, 2014. PMID: 24436047. DOI: 10.1158/2159-8290.CD-13-0639

8 Guillou L, Coindre JM, Bonichon F, Nguyen BB, Terrier P, Collin F, Vilain MO, Mandard AM, Le Doussal V, Leroux A, Jacquemier J, Duplay H, Sastre-Garau X and Costa J: Comparative study of the National Cancer Institute and French Federation of Cancer Centers Sarcoma Group grading systems in a population of 410 adult patients with soft tissue sarcoma. J Clin Oncol 15(1): 350-362, 1997. PMID: 8996162. DOI: 10.1200/JCO.1997.15.1.350

9 Mandahl N: Methods in solid tumour cytogenetics. In: Human cytogenetics: malignancy and acquired abnormalities. Rooney DE (ed.). Oxford University Press: New York, pp. 165-203, 2001.

10 McGowan-Jordan J, Simons A and Schmid M: ISCN 2016: An International System for Human Cytogenomic Nomenclature Karger: Basel, pp. 140, 2016.

11 Agaram NP, Chen CL, Zhang L, LaQuaglia MP, Wexler L and Antonescu CR: Recurrent MYOD1 mutations in pediatric and adult sclerosing and spindle cell rhabdomyosarcomas: evidence for a common pathogenesis. Genes Chromosomes Cancer 53(9): 779-787, 2014. PMID: 24824843. DOI: 10.1002/gcc.22187

12 Kohsaka S, Shukla N, Ameur N, Ito T, Ng CK, Wang L, Lim D, Marchetti A, Viale A, Pirun M, Socci ND, Qin LX, Sciot R, Bridge J, Singer S, Meyers P, Wexler LH, Barr FG, Dogan S, Fletcher JA, Reis-Filho JS and Ladanyi M: A recurrent neomorphic mutation in MYOD1 defines a clinically aggressive subset of embryonal rhabdomyosarcoma associated with PI3KAKT pathway mutations. Nat Genet 46(6): 595-600, 2014. PMID: 24793135. DOI: 10.1038/ng.2969

13 Szuhai K, de Jong D, Leung WY, Fletcher CD and Hogendoorn PC: Transactivating mutation of the MYOD1 gene is a frequent event in adult spindle cell rhabdomyosarcoma. J Pathol 232(3): 300-307, 2014. PMID: 24272621. DOI: 10.1002/path.4307

14 Rekhi B, Upadhyay P, Ramteke MP and Dutt A: MYOD1 (L122R) mutations are associated with spindle cell and sclerosing rhabdomyosarcomas with aggressive clinical outcomes. Mod Pathol 29(12): 1532-1540, 2016. PMID: 27562493. DOI: $10.1038 /$ modpathol.2016.144

15 Walther C, Mayrhofer M, Nilsson J, Hofvander J, Jonson T, Mandahl N, Ora I, Gisselsson D and Mertens F: Genetic heterogeneity in rhabdomyosarcoma revealed by SNP array analysis. Genes Chromosomes Cancer 55(1): 3-15, 2016. PMID: 26482321. DOI: $10.1002 / \mathrm{gcc} .22285$
16 Chiles MC, Parham DM, Qualman SJ, Teot LA, Bridge JA, Ullrich F, Barr FG, Meyer WH and Soft Tissue Sarcoma Committee of the Children's Oncology G: Sclerosing rhabdomyosarcomas in children and adolescents: a clinicopathologic review of 13 cases from the Intergroup Rhabdomyosarcoma Study Group and Children's Oncology Group. Pediatr Dev Pathol 7(6): 583-594, 2004. PMID: 15630526. DOI: $10.1007 / \mathrm{s} 10024-004-5058-\mathrm{x}$

17 Croes R, Debiec-Rychter M, Cokelaere K, De Vos R, Hagemeijer A and Sciot R: Adult sclerosing rhabdomyosarcoma: cytogenetic link with embryonal rhabdomyosarcoma. Virchows Arch 446(1): 64-67, 2005. PMID: 15660283. DOI: 10.1007/s00428-004-1131-0

18 Zambrano E, Perez-Atayde AR, Ahrens W and Reyes-Mugica M: Pediatric sclerosing rhabdomyosarcoma. Int J Surg Pathol 14(3): 193-199, 2006. PMID: 16959698. DOI: 10.1177/ 1066896906290558

19 Mentrikoski MJ, Golden W, Bourne TD and Legallo R: Spindle cell rhabdomyosarcoma of the neck with $\mathrm{t}(6 ; 8)$ translocation: report of a case and literature review. Pediatr Dev Pathol 16(1): 35-38, 2013. PMID: 23113671. DOI: 10.2350/12-04-1180-CR.1

20 Mosquera JM, Sboner A, Zhang L, Kitabayashi N, Chen CL, Sung YS, Wexler LH, LaQuaglia MP, Edelman M, Sreekantaiah C, Rubin MA and Antonescu CR: Recurrent NCOA2 gene rearrangements in congenital/infantile spindle cell rhabdomyosarcoma. Genes Chromosomes Cancer 52(6): 538550, 2013. PMID: 23463663. DOI: $10.1002 / \mathrm{gcc} .22050$

21 Rubin BP, Hasserjian RP, Singer S, Janecka I, Fletcher JA and Fletcher CD: Spindle cell rhabdomyosarcoma (so-called) in adults: report of two cases with emphasis on differential diagnosis. Am J Surg Pathol 22(4): 459-464, 1998. PMID: 9537474. DOI: 10.1097/00000478-199804000-00011

22 Gil-Benso R, Carda-Batalla C, Navarro-Fos S, Pellin-Perez A and Llombart-Bosch A: Cytogenetic study of a spindle-cell rhabdomyosarcoma of the parotid gland. Cancer Genet Cytogenet 109(2): 150-153, 1999. PMID: 10087951. DOI: 10.1016/s0165-4608(98)00163-0

23 Debiec-Rychter M, Hagemeijer A and Sciot R: Spindle-cell rhabdomyosarcoma with 2q36 approximately q37 involvement. Cancer Genet Cytogenet 140(1): 62-65, 2003. PMID: 12550761. DOI: $10.1016 / \mathrm{s} 0165-4608(02) 00647-7$

24 Mitelman F, Johansson B and Mertens F: Mitelman Database of Chromosome Aberrations and Gene Fusions in Cancer, 2020. Available at: https://mitelmandatabase.isb-cgc.org/

25 Alaggio R, Zhang L, Sung YS, Huang SC, Chen CL, Bisogno G, Zin A, Agaram NP, LaQuaglia MP, Wexler LH and Antonescu CR: A molecular study of pediatric spindle and sclerosing rhabdomyosarcoma: Identification of novel and recurrent VGLL2-related fusions in infantile cases. Am J Surg Pathol 40(2): 224-235, 2016. PMID: 26501226. DOI: 10.1097 /PAS.0000000000000538 